Editorial

\title{
Acknowledgement to Reviewers of Green Energy and Sustainability
}

GES Editorial Office

4505 Pacific HWY E, Fife, WA 98424, USA; E-Mail: ges@pivotscipub.com

Received: 17 Dec 2021

Accepted: 18 Dec 2021

Published: 24 Dec 2021

Copyright: (c) 2021 by the author(s). This is an Open Access article distributed under the terms of the Creative Commons License Attribution 4.0 International (CC BY 4.0), which permits unrestricted use, distribution, and reproduction in any medium or format, provided the original work is correctly credited.

Publisher's Note: Pivot Science Publication Corp. remains neutral with regard to jurisdictional claims in published maps and institutional affiliations.

On behalf of the entire journal team, we would like to express our gratitude to the scientists who contributed their valuable expertise and time in reviewing manuscripts for the journal Green Energy and Sustainability.

Peer review is one of the most important processes that we rely on for assessing the quality of submissions. The reviewer's comments have been key to improving the quality of the papers published in Green Energy and Sustainability. We greatly appreciate the following reviewers for their generous support of Green Energy and Sustainability in 2021.

Note: This list reflects reviews received between January 1, 2021, and December 20, 2021; names listed in alphabetical order.

Reza Alizadeh

Constantinos A. Balaras

Peter Brimblecombe

Celina Filippín

Pantazis Georgiou

Effrosyni Giama

Kosmas Kavadias

Kevin Keene

Wilhelm Kuckshinrichs

Elli Kyriaki

Andreas Mamolos

Emmanouil Mathioulakis

Dimitris Missirlis
Agis Papadopoulos

Athanasios I. Papadopoulos

Konstantinos Papakostas

Georgios N. Psarros

Daniel Scholten

Manolis Souliotis

Theodoros Theodosiou

Antonios Tourlidakis

Katerina Tsikaloudaki

Stella Tsoka

Theocharis Tsoutsos

Ad J.M. van Wijk

Ewa Zender-Świercz

Cite this article: GES Editorial Office. Acknowledgement to Reviewers of Green Energy and Sustainability. Green Energy Sustain. 2021;1,2. https://doi.org/10.47248/HKOD902101020008 